\title{
UTILIZAÇÃO DE SISTEMA DE INFORMAÇÃO GE OGRÁFICA NA AVALIAÇÃO DO USO DA TERRA EM BOTUCATU (SP) $)^{(\mathbf{1})}$
}

\author{
J . B.T. RODRIGUES ${ }^{(2)}$, C. R. L. ZIMBACK ${ }^{(3)}$ \& E. L. PIROLI (4)
}

\begin{abstract}
RESUMO
Foi utilizado o SIG-IDRISI, com o objetivo de verificar a adequação do uso da terra em 1997/98, na parte inicial da Bacia do Rio Pardo, Botucatu/Pardinho (SP), visando à obtenção de subsídios para o planejamento adequado do uso da área. As classes e subclasses de capacidade de uso foram determinadas de acordo com o Sistema de Classificação da Capacidade de Uso das Terras. As terras da área estudada foram discri minadas como: classe Vle, terras susceptíveis à erosão (90,49\%); classe Va, terras planas, não-sujeitas à erosão, limitadas por excesso de água $(3,48 \%)$; classe IVe, terras severamente limitadas por ri sco de erosão $(0,50 \%)$; classe IIIa, terras planas com excesso de água (3,34\%); classe IIIe, terras com declividade moderada e deflúvio rápido, riscos severos de erosão (1,32\%); e classe Ile, terras produtivas, com risco ligeiro a moderado de erosão $(0,87 \%)$. Pela análise conjunta da capacidade de uso e do uso atual das terras, verificouse que $89,28 \%$ das áreas não apresentaram conflito de utilização; $2,24 \%$ estavam cultivadas com culturas anuais e perenes, adequação para tal uso, e 8,48\% da área com pastagens deveria ser substituída por reflorestamento e, ou, preservação ambiental.
\end{abstract}

Termos de indexação: manejo do solo, geoprocessamento, classificação de terras.

(1) Grupo de Estudos e Pesquisas Agrárias Georreferenciadas - GEPAG/FCA, Universidade Estadual Paulista - UNESP. Recebido para publicação em outubro de 2000 e aprovado em abril de 2001.

(2) Engenheiro-Agrônomo, Pós-graduando no curso de Energia na Agricultura, Faculdade de Ciências Agronômicas, Universidade Estadual Paulista - UNESP. Caixa Postal 237, CEP 18603-970 Botucatu (SP). E-mail: btjb.zaz.com.br

(3) Professora do Departamento de Recursos Naturais, FCA/U NESP. E-mail czimback@fca.unesp.br

(4) Engenheiro Florestal, Pós-graduando no curso de Energia na Agricultura, Faculdade de Ciências Agronômicas, UNESP. E-mail: piroli@fca.unesp.br 


\title{
SUMMARY: UTILIZATION OF A GEOGRAPHIC INFORMATION SYSTEM ON LAND USE EVALUATION IN BOTUCATU (SP)
}

\begin{abstract}
TheGIS-IDRISI was used to check land useadequacy from 1997 to 1998, in theinitial part of the Rio Pardo basin, in Botucatu/ Pardinho (SP), to obtain a suitable land use planning of thearea. Thedasses and subclasses of land capability weredetermined according to the Land Capability Classification System. Thelands of thestudied area wereclassified as: Class VI e, lands with erosi on suscepti bi lity (90.49\%); class Va, flat lands, with no erosi on risk, but limited by excess of water (3.48\%); dass III a, flat lands with excess of water (3.34\%); class IIIe, lands with moderate slope and fast run-off, under severe erosion risk (1.32\%); class II e, productive lands, with small-to-moderate risk of erosion (0.87\%); and class IVe, lands strongly limited by risk of erosion (0.50\%). Based on the analysis of the current land use, it $89.28 \%$ of thearea did not show conflict between theland capability and actual land use; $2.24 \%$ of thearea was used with annual or perennial crops, but in lands with unsuitable for crops; and $8.48 \%$ of the area should be converted to forest and, or, environmental protection.
\end{abstract}

Index terms: Iand use, GIS, soil management.

\section{NTRODUÇÃO}

A capacidade de uso da terra é a sua adaptabilidade para fins diversos, sem que sofra depauperamento pelos fatores de desgaste e empobrecimento, sendo considerada por Lepsch (1991) como uma poderosa ferramenta utilizável no seu planejamento e uso. Pela classificação da capacidade de uso, a terra tem definida a sua possibilidade de ser utilizada para culturas anuais, culturas perenes, pastagens, refl orestamento ou vida silvestre, sem sofrer danos consideráveis. Essa capacidade de uso da terra é classificada por meio de um sistema que leva em conta o clima, a intensidade do uso, os fatores limitantes, as características e propriedades físicas do solo, os impedimentos à motomecanização e as condições de infra-estrutura (Lepsch, 1991). A capacidade de uso da terra tem por finalidade fornecer importante subsídio para o planejamento, funcionando como uma ferramenta que imprime um caráter seletivo, racionalizador e de orientação ao uso das terras.

Almeja-se representar, no mapa de capacidade de uso, a divisão da área, conforme a avaliação da capacidade de uso das terras. O meio comumente utilizado para a obtenção deste mapa era a confecção e sobreposição de mapas analógicos. Atualmente, esta tarefa é passível de ser desempenhada por um Sistema de I nformação Geográfica (SIG), que é um conjunto de ferramentas digitais para aquisição, análise e divulgação de informações espaciais. Esse sistema permite o exame de um amplo conjunto de variáveis que são usualmente consideradas em decisões de manejo das terras (Marble, 1990; Petersen et al., 1995).
Um Sistema de Informação Geográfica é constituído por um conjunto de módul os computacionais destinados à aquisição, armazenamento, recuperação, transformação e saída de dados espacial mente distribuídos. Estes dados geográficos descrevem objetos do mundo real sob três aspectos: (a) seu posicionamento com relação a um sistema de coordenadas; (b) seus atributos, e (c) as relações topológicas existentes. Deste modo, é possível trabal har com dados dos quais se conhecem a posi ção geográfica, o valor da característica naquel e ponto e a sua estrutura de relacionamento espacial, tais como: vizinhança, proximidade e pertinência entre objetos geográficos. Por isso, um SIG pode ser utilizado em estudos relativos ao meio ambiente, na pesquisa da previsão de determinados fenômenos ou no apoi oa decisões de planejamento, considerando a concepção de que os dados armazenados representam um modelo real (Burrough, 1986). Alguns exemplos de utilização de SIG (Formaggio et al., 1992; Assad, 1995) demonstram sua viabilidade para estudos de problemas ambientais.

Um modo de verificar a adequação do uso da terra é o confronto do uso atual com as classes de capacidade de uso, semel hante aos estudos efetuados por Formaggio et al. (1992) e Silva et al. (1993). O mapa de uso atual tem também no SIG um forte aliado para sua confecção, por meio de composições coloridas de imagens obtidas por sensoriamento remoto. O seu usoajuda a identificar diferentes alvos relativos à cobertura e, ou, ao uso da terra, submetendo-se a imagem de satélite a um processo de classificação multiespectral. Segundo Crósta (1992), o processo consiste em atribuir cada pixel a uma categoria de um grupo de classes, podendo ser 
a classificação supervisionada (interferindo-se na identificação das classes desejadas) ou não supervisionada (totalmenterealizada pel o sistema).

Objetivou-se, neste trabal ho, utilizar os recursos do SIG-IDRISI (Eastman, 1997) na obtenção do mapa de classes de capacidade de uso das terras e do mapa de uso atual, com posterior identificação de áreas de conflito entre esses mapas.

\section{MATERIAL E MÉTODOS}

A área de estudo refere-se à bacia do Córrego Água da Madalena, afluente do Rio Pardo, região de B otucatu/Pardinho (SP), cujas coordenadas de referência são $22^{\circ}$ 53' de latitude sul e $48^{\circ} 27^{\prime}$ longitude WGr (IBGE, 1982), com área de 746,5 ha. Apresenta clima Cwa, segundo a classificação de Köppen e, conforme EMBRAPA (1988), vegetação natural de Floresta Tropical Subperenifólia.

Deacordo com IPT (1981), na região, afloram duas formações geológicas: nas partes mais altas, aparecem arenitos pertencentes ao Grupo Bauru, Formação Marília, e, nas áreas mais baixas, margeando os cursos d'água, rochas basálticas do Grupo São Bento, Formação Serra Geral. Os solos que compõem a bacia são: Latossolo Vermelho, Argissolo Vermelho-Amarelo, Neossolo Litólico e Gleissol os indiscriminados (Zimback, 1997). Para a digitalização das curvas de nível, foram utilizadas cartas planialtimétricas, em escala 1:10.000. O mapa de sol os para a digitalização, com escala idêntica, é parte integrante dolevantamento semidetal hado da área, do qual foram também utilizadas as análises de solo. Foram digitalizadas as curvas de nível, de 20 em 20 metros $^{(5)}$, utilizando o software TOSCA (J ones, 1995) e mesa digitalizadora, procedendo-se igualmente à digitalização das unidades de mapeamento.

A interpolação dos valores entre as curvas de nível, pelo método de interpolação de isolinhas disponível no sistema, foi efetuada para obter o modelo numérico do terreno. Os valores de declividade foram calculados para este modelo e agrupados em interval os definidos para estudos de conservação de solos, visando à geração do mapa de classes de declive. As faixas de declividade consideradas, em percentagem, foram de 0 a 3; 3 a 6 ; 6 a 12; 12 a 20; 20 a 40, e acima de 40.

Foi efetuado o cruzamento do mapa de classes de declive com o mapa que continha as unidades de mapeamento de solo, obtendo-se uma gama de associações que serviram de ponto de partida para a determinação das classes de capacidade de uso.
As classes e as subclasses de capacidade de uso foram determinadas de acordo com o sistema de dassificação constantedo Manual para L evantamento Utilitário do Meio Físico e Classificação de Terras no Sistema de Capacidade de Uso (Lepsch, 1991). Para a classificação, seguiram-se os critérios constantes da tabela de julgamento confeccionada conforme Lepsch (1991) e de acordo com adaptação regional compilada por Zimbadk \& Rodrigues (1993).

O mapa de dasses de capacidade de uso foi gerado a partir da alteração dos valores referentes a cada associação de tipo de solo e classe de declive. Deste modo, cada associação assumiu o identificador da respectiva classe a que foi designada, após ter sido submetida à classificação de acordo com os critérios de fertilidade aparente, profundidade efetiva, permeabilidade edrenagem, deflúvio, pedregosidade, risco de inundação, dedividade e erosão (laminar, em sulcos e voçorocas), estabelecidos na referida tabela de julgamento.

Para obter o mapa de uso atual, foi utilizada a imagem LANDSAT TM220_076A de 04-08-97. Pontos de controle foram obtiōos nas cartas para o georreferenciamento da imagem. Na classificação da imagem desatélite, foram utilizadas as bandasTM 3 , 4 e 5, LANDSAT, comumente utilizadas em classificação de imagens de satélite, por reunirem a porção mais significativa das informações de resposta espectral. A composição col orida foi obtida pela combinação das bandas adotadas na seqüência 3, 5 e 4. Optou-se pela classificação supervisionada, sendo definido o uso para cada polígono de referência, conforme o reconhecimento das feições predominantes na composição col orida.

O método de classificação utilizado foi o de mínima distância da média, que agrupou os pixels que apresentaram a menor distância em relação à média dos valores contidos em cada polígono de referência. Para avaliar a adequação de uso das terras, efetuou-se o cruzamento do mapa de classes de capacidade de uso com o mapa de uso atual oriundo da classificação da imagem.

\section{RESULTADOS E DISCUSSÃO}

O mapa de sol os digitalizado forneceu o arquivo digital dos polígonos que representam os contornos das unidades de mapeamento, convertido para o formato "raster" peloIDRISI (Figura 1).

As unidades de solo que ocorrem na região estudada ocupam, respectivamente, a área de 16,0 ha (Latossol oVermel ho distrófico relevo ondulado-LV2),

\footnotetext{
${ }^{(5)}$ Embora as cartas topográficas apresentem curvas com eqüidistância vertical de cinco metros, foram extraídas somente aquelas com eqüidistância de 20 metros, dada a impossibilidade de ajustar a resolução de saída à quantidade de curvas existentes na parte da carta que abrange a Cuesta de Botucatu.
} 
55,0 ha (Gleissolos indiscriminados - Gi), 675,5 ha (Argissolo Vermel ho-Amarelo distrófico - PVA).

A digitalização das curvas de nível gerou uma série de arquivos "vetoriais", os quais foram convertidos para o formato "raster". A imagem topográfica formou-se com o agrupamento desses arquivos. Sobre esta imagem basearam-se todos os procedimentos de interpolação dos valores de altitude e cálculo de declividade que culminaram com a obtenção do mapa de classes de declive (Figura 2). Da associação do mapa de sol os com o de classes de declive, obteve-se uma imagem intermediária que permitiu a reclassificação dos vários tipos de associação presentes nas respectivas classes de capacidade de uso. Desse procedimento resultou a imagem correspondente ao Mapa de Classes de Capacidade de Uso (Figura 3), cujas áreas estão listadas no quadro 1.

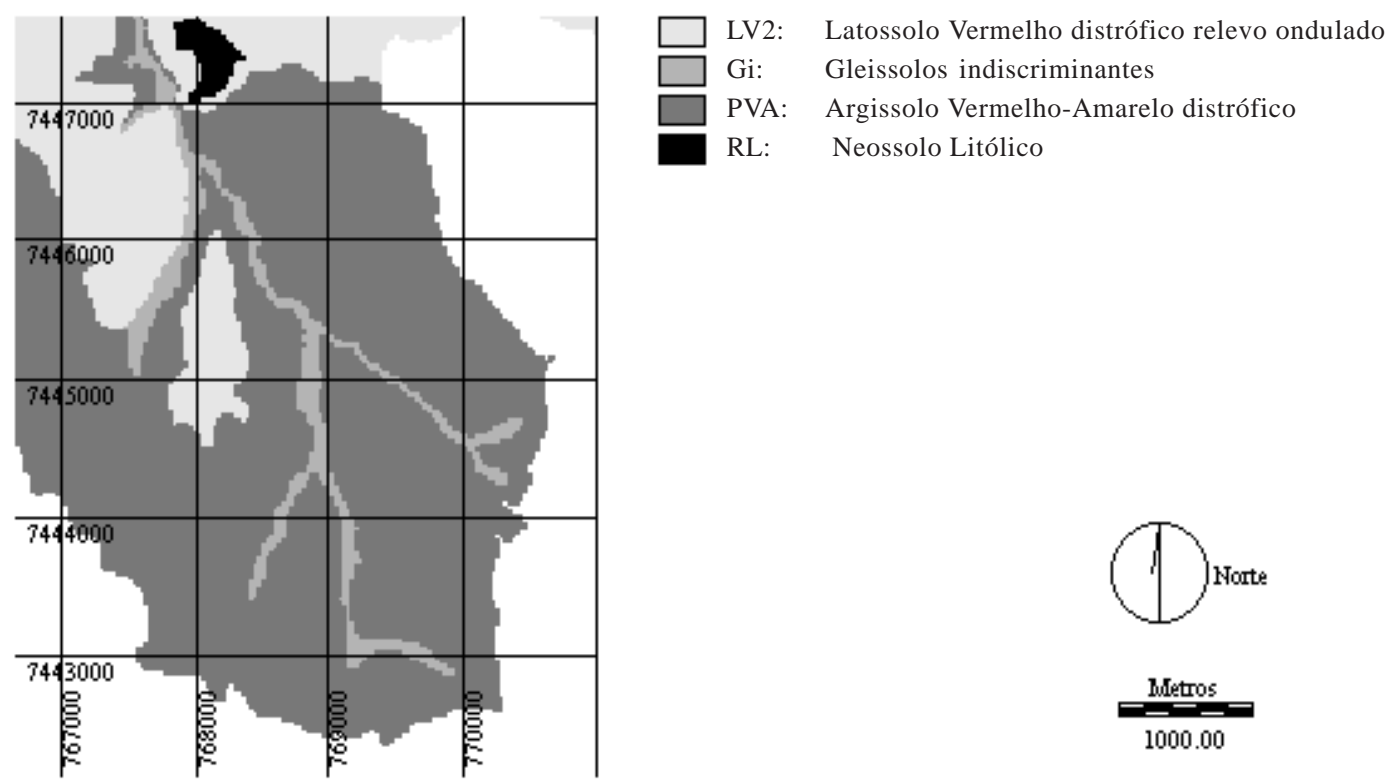

Figura 1. Mapa de solos (formato raster).
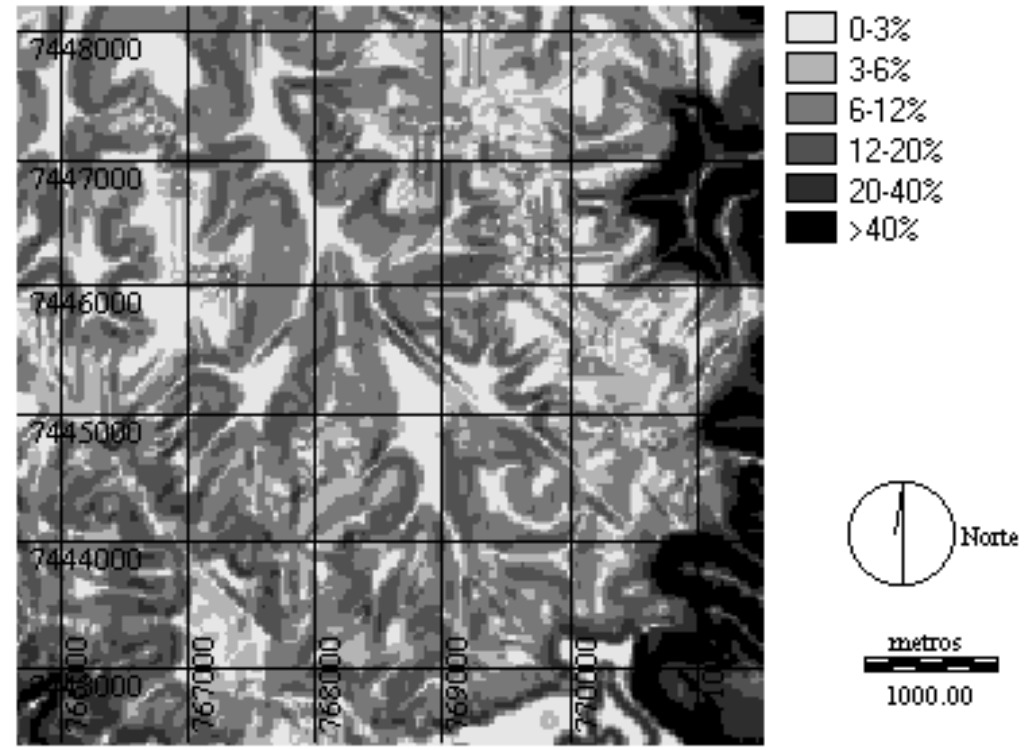

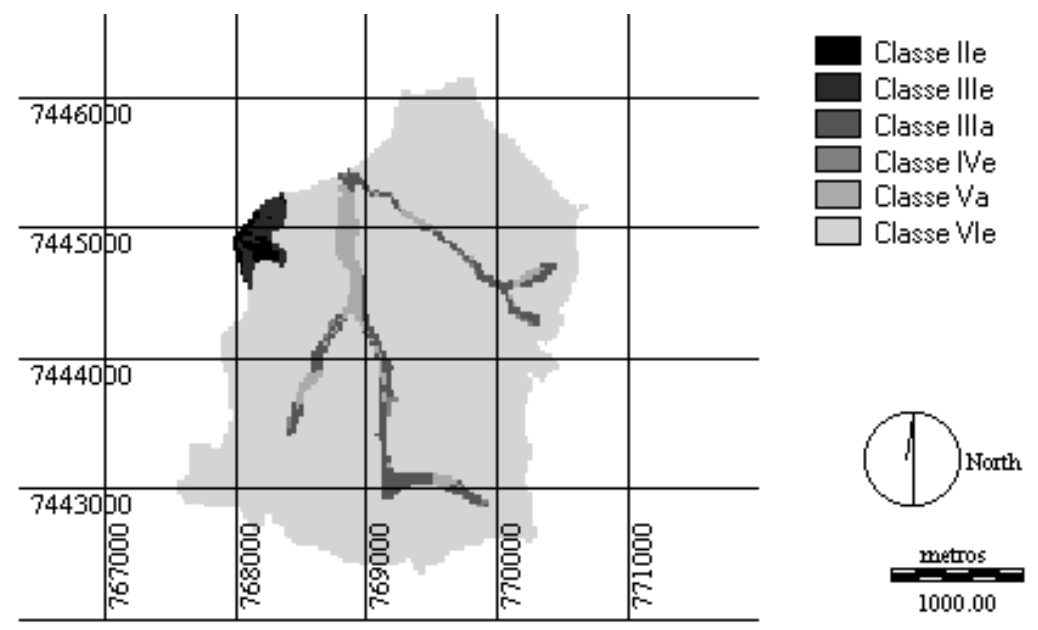

Figura 3. Mapa de classes de capacidade de uso.

Quadro 1. Áreas das classes/subclasses de capacidade de uso

\begin{tabular}{ccc}
\hline $\begin{array}{c}\text { Classe/subclasse } \\
\text { de capacidade de uso }\end{array}$ & Área ocupada & $\begin{array}{c}\text { Participação } \\
\text { na área total }\end{array}$ \\
\hline & ha & $\%$ \\
I lie & $($ zero) & - \\
IIle & 6,5 & 0,87 \\
IIIa & 9,9 & 1,32 \\
I ve & 24,9 & 3,34 \\
Va & 3,7 & 0,50 \\
Vie & 26,0 & 3,48 \\
Total & 675,5 & 90,49 \\
\end{tabular}

As classes/subclasses de capacidade de uso obtidas para a área de estudo são definidas assim, segundo Lepsh (1991):

Ile - Terras produtivas, com relevo suavemente ondulado, oferecendoligeiroa moderado risco de erosão.

IIle - Terras com declividade moderada, relevo suavemente ondulado a ondulado, deflúvio rápido, riscos severos de erosão quando o solo está descoberto de vegetação, podendo apresentar erosão laminar moderada e, ou, sulcos superficiais e rasos freqüentes.

III a - Terras planas com limitações moderadas por excesso deágua, mas sem riscos de inundação. A drenagemé possível, mas a sua manutenção é complexa.

IVe - Terras severamente limitadas por risco de erosão para cultivos intensivos, geralmente com declividade acentuada, deflúvio muito rápido, podendo apresentar erosão em sulcos superficiais muito freqüentes, em sulcos rasos freqüentes, ou em sulcos profundos ocasionais.

Va - Terras planas não-sujeitas à erosão, com deflúvio praticamente nulo, severamente limitadas por excesso deágua, sem possibilidade de drenagem artificial e, ou, com risco de inundação freqüente, mas que podem ser usadas para pastoreio, pelo menos em algumas épocas do ano.

VIe - Terras que, sob pastagem (ou, eventual mente, com culturas permanentes protetoras do solo), são medianamente susceptíveis à erosão, com relevo forte ondulado e declividade acentuada, deflúvio moderado a severo; dificuldadesevera para a motomecanização em decorrência das condições topográficas, risco de erosão que pode chegar a muito severo e presença de erosão em sulcos rasos muito freqüentes ou sulcos profundos freqüentes.

Efetuando a classificação supervisionada da imagem de satélite, obteve-se o mapa de uso atual, confrontado então com o mapa de capaci dade de uso das terras, resultando numa dezena de combi nações cuja análise permitiu a detecção de três segmentos relativos à presença ou ausência de conflito aparente na ocupação das terras. Os resultados mostraram que $89,28 \%$ das áreas não apresentaram conflito de utilização; 2,24\% encontravam-se cultivadas com culturas anuais e perenes, sem, contudo, apresentar adequação para tal uso, e 8,48\% das áreas com pastagem, onde geralmente não são adotadas medidas de conservação de solo, deveriam ser substituídas por reflorestamento e, ou, preservação ambiental. A distribuição destas áreas é ilustrada na figura 4. 


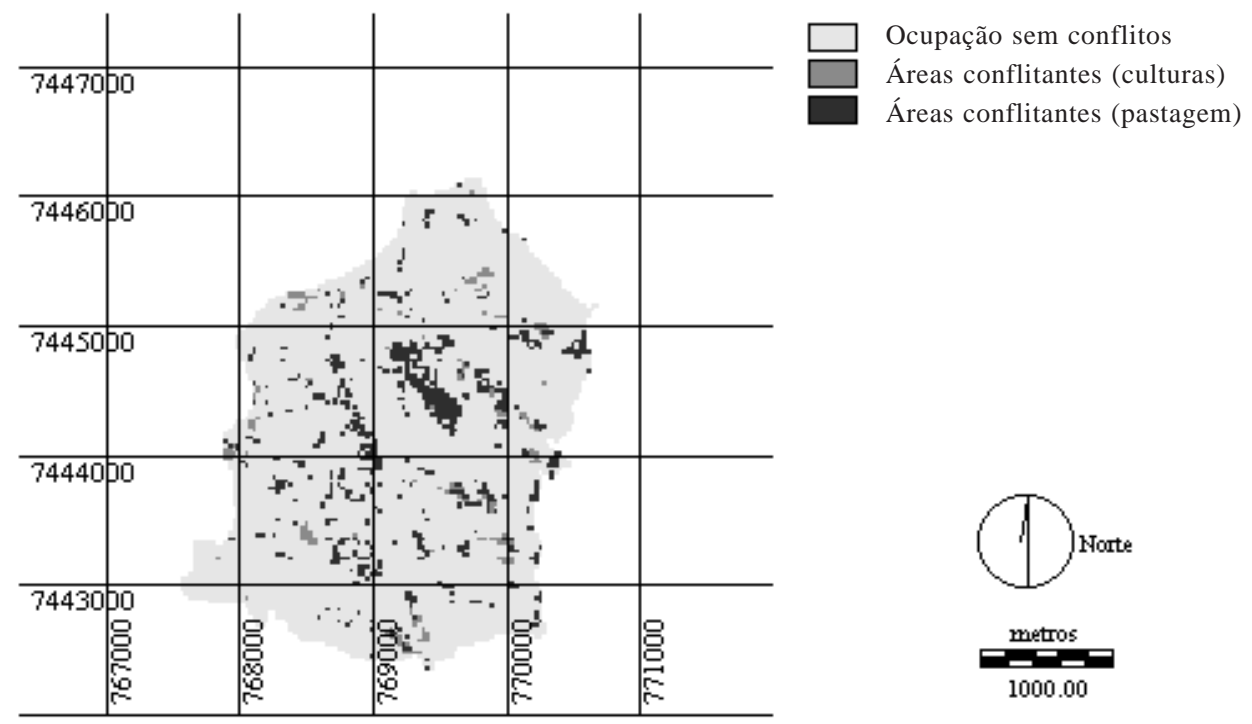

Figura 4. Mapa de adequação de uso (uso adequado x uso atual).

Duranteo processo de dassificaçãosupervisionada, nas áreas ocupadas por pastagem, ao delimitar polígonos mais abrangentes, que incluíam pixels, cujos valores expressavam maior amplitude de variação, não foi possível a caracterização numa categoria única, pois a imagem resultante não expressava uma delimitação adequada desta categoria de uso. Isso se deu, provavelmente, em virtude da influência que o relevo acentuado e irregular da região pode exercer sobre o nível de resposta espectral oferecido pelo mesmo tipo de cobertura, em áreas contíguas, que apresentam relevos diferenciados.

Criando polígonos específicos às áreas que exibiam variação na tonalidade dos pixels (indicando que havia notadamente um nível de reflectância diferenciado, embora reconhecidamenteapresentando um uso único), obteve-se um mapa que seaproximava mais das feições exibidas na composição colorida. Com o incremento do rigor na definição destes polígonos de referência, diferenciaram-se as áreas de pastagem nas mais variadas condições de relevo e nível de conservação.

Desconsiderando as citadas diferenciações exigidas para a exi bição mais representativa douso da terra, as áreas de pastagem ocupam visivel mente a maioria das terras compreendidas na área de estudo (514,0 ha). As áreas de mata restringem-seà vegetação remanescente em torno das nascentes do Rio Pardo e al guns trechos de mata ciliar. Observouse ausência de continuidade da mata ciliar aolongo dos cursos d'água, demonstrando que parte dos proprietários não a preserva em suas propriedades. Fora destas condições, percebeu-se apenas pequeno fragmento de mata mais significativo, próximo ao perímetro urbano. A área total de mata nativa contabilizou 97,2 ha, correspondente a apenas 13\% da área de estudo).

A identificação do perímetro de ocupação com o uso caracterizado como "área urbana" (aproximadamente $11 \%$ da área) representou uma tarefa difícil de ser efetuada com a precisão desejável, uma vez que esta categoria foi classificada nos mais variados pontos do mapa de uso atual, e não como um núcleo razoavel mente circunscrito e característico.

A dificuldade de selecionar eficientemente um conjunto de pixels que sejam ao mesmo tempo homogêneos e representativos do uso como área urbana reside, basicamente, na diversidade de padrões de resposta espectral possível de obter no espaço urbano. Uma vez que nel econvivem inúmeros tipos de cobertura do solo (asfalto, edificações diversas, praças, terrenos vegetados ou sem vegetação, árvores, estradas de terra, entre outros), cada um apresenta o seu padrão de resposta característico.

A obtenção do mapa de capacidade de uso e do mapa de uso atual por meio dos recursos oferecidos pelo SIG integra uma parte do processo de identificação de problemas de manejo e conservação oriundos de uso inadequado e serve como parâmetro de indicação para novas atividades mais propícias à conservação das terras e dos recursos hídricos, na busca de uma maior eficiência na adequação do uso e manejo do solo, em relação às recomendações pertinentes a cada classe.

A utilização de um SIG na confecção de mapas mostrou-se bastante vantajosa pela rapidez e pelo amplo conjunto de alternativas de integração dos dados deatributos e dados espaciais no processamento e manipulação da base de dados. 


\section{CONCLUSÕES}

1. As terras da área estudada foram discriminadas como: classe VIe $(90,49 \%)$; classe Va $(3,48 \%)$; classe IVe (0,50\%); classe III a (3,34\%); classe III e $(1,32 \%)$ e classe Ile $(0,87 \%)$.

2. Foram encontradas áreas sem conflito aparente $(89,28 \%)$; áreas com inadequada intensidade de uso (10,72\%, sendo $2,24 \%$ com culturas e $8,48 \%$ com pastagens).

3. Nas áreas com conflito de uso, as que se encontram com culturas deverão ter sua exploração alterada para outras de menor intensidade de uso, enquanto as mantidas com pastagem devem ser destinadas ao reflorestamento e, ou, preservação ambiental.

\section{LITERATURA CITADA}

ASSAD, M.L.L. Uso de um sistema de informações geográficas na determinação da aptidão agrícola de terras. R. Bras. Ci. Solo, 19:133-139, 1995.

BURROUGH, P.A. Principles of geographical information systems for land resource assessment. New York, Oxford University Press, 1986. 194p.

CRÓSTA, A.P. Processamento digital de imagens de sensoriamento remoto. Campinas, Universidade de Campinas, 1992. 170p.

EASTMAN, J .R. IDRISI for Windows - User's guide. Version 2.0. Massachusettes, Clark University, 1997.

EMPRESA BRASILEIRA DE PESQUISA AGROPECUÁRIA EMBRAPA. Serviço Nacional de Levantamento e Conservação de Solos. Critérios para distinção de classes de solos e de fases de unidades de mapeamento - normas em uso peloSNLCS. Rio deJ aneiro, 1988. 65p. (Documento, 11)
FORMAGGIO,A.R.;ALVES, S.D. \& EPIPHANIO,J .C.N. Sistemas de informações geográficas na obtenção de mapas de aptidão agrícola e de taxa de adequação de uso das terras. R. Bras. Ci. Solo, 16:249-256, 1992.

INSTITUTO BRASILEIRO DE GEOGRAFIA E ESTATÍSTICA - IBGE. Secretaria de Planejamento da Presidência da República. Carta do Brasil - Quadrículas de Botucatu e Pardinho. Rio de J aneiro, 1982. Escala 1:50.000.

INSTITUTO DE PESQUISAS TECNOLÓGICAS DO ESTADO DE SÃO PAULO - IPT-SP. Mapa geológico do Estado de São Paulo. São Paulo, 1981, 2v. Escala 1:500.000.

J ONES,J .R. Tosca. Reference guide. Version 2.12. Massachusetts, Clark University, 1995. 86p.

LEPSCH, I.F., coord. Manual para levantamento utilitário do meio físico e dassificação deterras no sistema de capacidade de uso. Campinas, Sociedade Brasileiro Ciência do Solo, 1991. 175p.

MARBLE, D.F. Geographic information systems: an overview. In: PEUQUET, D.J. \& MARBLE, D.F., eds. Introductory readings in geographic information systems. New York, Taylor and Francis, 1990. p.8-17.

PETERSEN, G.W.; BELL, J.C.; MCSWEENEY, K.; NIELSEN, A.G. \& ROBERT, P.C. Geographic information systems in agronomy. Adv. Agron., 55:67-111, 1995.

SILVA, J .R.C.; DEGLORIA, S.D.; PHILIPSON, W.R. \& MCNEIL, R.J. Estudo da mudança de uso da terra através de um sistema de análise georreferenciada. R. Bras. Ci. Solo, 17:451-457, 1993.

ZIMBACK, C.R.L. Levantamento semidetalhado dos solos da bacia do Rio Pardo nos Municípios de Pardinho e Botucatu. Botucatu, Universidade Estadual Paulista J úlio de Mesquita Filho, 1997. 55p.

ZIMBACK, C.R.L. \& RODRIGUES, R.M. Determinação da capacidade de uso das terras da Fazenda São Manuel. Botucatu, Universidade Estadual Paulista J úlio de Mesquita Filho, 1993. 36p. 
J .B.T. RODRIGUES et al. 